\title{
Transportation Policymaking in Beijing and Shanghai: Contributors, Obstacles and Process
}

\author{
Jungwoo Chun \\ Department of Urban Studies \& Planning \\ Massachusetts Institute of Technology \\ 77 Massachusetts Avenue, Rm 9-569, Cambridge, MA 02139 \\ Tel: 617-319-8324; Email: jwchun@mit.edu \\ Joanna Moody \\ Interdepartmental Program in Transportation \\ Massachusetts Institute of Technology \\ 77 Massachusetts Avenue, Rm 1-151, Cambridge, MA 02139 \\ Tel: 434-409-5679; Email: jcmoody@mit.edu \\ Jinhua Zhao (corresponding author) \\ Edward H. and Joyce Linde Associate Professor of City and Transportation Planning \\ Department of Urban Studies \& Planning \\ Massachusetts Institute of Technology \\ 77 Massachusetts Avenue, Rm 9-523, Cambridge, MA 02139 \\ Tel: 617-324-7594; Email: jinhua@mit.edu
}

Word count (excluding references and abstract): 7,417

\section{ACKNOWLEDMENTS}

The authors would like to thank all of the subjects of our interviews for their time and detailed commentary. We also acknowledge our colleagues in the MIT JTL Urban Mobility Lab who have contributed their critical commentary and support to this work, particularly Shenhao Wang and Xuenan Ni. This work was supported through the MIT Energy Initiative's Mobility of the Future study. 


\section{HIGHLIGHTS}

- Identifies policy learning, data informatization and public opinion as contributors

- Identifies public complaint, unilateral and fragmented decision-making as obstacles

- Suggests indirect public participation is both a contributor and obstacle

- Proposes processual model for transportation policymaking in Chinese megacities

- Discusses lack of adaptiveness and potential for city-level policy experimentation 


\title{
Transportation Policymaking in Beijing and Shanghai: Contributors, Obstacles and Process
}

\begin{abstract}
5 With continued motorization and urbanization in Chinese cities, there is a growing demand for innovative transportation policies at the city level to address the challenges of congestion, local air pollution, and greenhouse gas emissions. Using Beijing and Shanghai as case studies, this paper draws on 32 in-depth semi-structured interviews with municipal government officials, academics, and transportation professionals to explore the city-level transportation policymaking process in

10 China. Across the two cities, we identify three common contributors - policy learning, data informatization, and public opinion - and four obstacles - public complaint, unilateral decisionmaking, inadequate coordination among relevant departments, and lack of adaptiveness in policy implementation practice - to adopting timely and appropriate transportation policies. We then introduce a processual model that connects the contributors and obstacles identified within the

15 flow of transportation policy among key actors in city-level government. This process shows how transportation policymaking in Chinese megacities is often reactive to public outcry over a transportation problem. This problem is investigated by a technical government research center that reports to the municipal transport committee. This committee then assesses public opinion and submits a policy recommendation to city government leadership, who make the final policy

20 decision. Based on both case studies, we discuss potential recommendations for how to better enable transportation policymaking at the city level in China through more formalized processes of policy experimentation and public participation. We conclude with a discussion of limitations and areas of future research.
\end{abstract}

Keywords: China municipal transportation policy, Beijing, Shanghai, policymaking process, public opinion 


\section{INTRODUCTION}

Chinese cities have been subject to accelerated urbanization and motorization over the past two decades, leading to issues such as congestion and air pollution (Gakenheimer, 1999). Nationwide, the growth rate of privately owned vehicles approached 30 percent in 2010 and a third of the world's 50 most congested cities were in China (Alam and Ahmed, 2013). According to the Ministry of Environmental Protection, only three cities in remote areas, among China's seventyfour major cities, met national standard for "fine air quality" in 2013 (Saikawa, 2014).

This trend poses challenges to city governments to develop policies to address urbanization and motorization. Although the Chinese national government sets a broad, national policy framework, city governments have autonomy to formulate and implement new urban transportation policy (Wan, Wang, and Sperling, 2013; Liang, 2014). In response, governments of major Chinese cities are actively seeking ways to implement new policy reforms and adopt updated strategic plans. However, within the transportation domain there is little scholarship around the underlying factors that affect policy decision at the city level.

This study characterizes the transportation decision-making processes in city governments in Beijing and Shanghai, China. Studying the internal operations of the Chinese government at any level and related to most policy areas is typically a challenge for international researchers. Yet with in-depth interviews and iterative qualitative data analysis, this study identifies existing contributors and obstacles to transportation policy implementation and investigates the transportation policy decision-making process. In the transportation context, we corroborate and add to existing literature on city-level policymaking by identifying three key contributors in the transportation context - policy learning from other cities, transportation informatization, and public opinion. We further identify four prominent obstacles to transportation policy decisions in Beijing and Shanghai - public complaint, unilateral decision-making structure, lack of crossdepartmental communication and coordination, and lack of adaptiveness in policy implementation. We then illustrate how these factors connect to policy decision outcomes by mapping them to a processual model of how policy flows from one actor to another in the city governments in Beijing and Shanghai. In each section examining contributors, obstacles, and process, we connect our findings for the transportation domain and the Chinese context to relevant literature in city-level policymaking. We then discuss how transportation policymaking in Beijing and Shanghai may benefit from more formalized processes of public participation and policy experimentation. We conclude with acknowledgment of the limitations of this study and a case for further research into transportation decision-making at the city level in China.

\subsection{Case Selection}

We conduct this study in two Chinese megacities: Beijing and Shanghai. These cities were chosen for several reasons. First, despite the differences in the political, institutional, and cultural conditions, the physical and economic characteristics of these two megacities are representative of conditions in many rapidly developing cities in the Global South. China's urban areas, which have grown by 350 million people over the past 30 years, have high population densities, rapidly rising incomes, and increasing rates of motorization (Woetzel et al., 2009). With these trends come congestion and pollution, which challenge other developing cities in South Asia and Latin

45 America. Second, China has a relatively strong government sector relative to its civil society and private sector and relative to some other less developed countries, which allows for a study of policymaking and implementation. 
Large Chinese cities like Shanghai and Beijing face urban transportation challenges including congestion, air pollution, energy shortages, and global climate change (Wang, 2010). To combat these issues, major Chinese cities are trying to adopt new urban transportation management strategies (Peng, 2005). While most policymaking power is vested in the national government in China, cities enjoy autonomy and discretion in policy implementation when addressing challenges of traffic congestion and local air pollution. Yang (2013) describes this model as "fragmented authoritarianism," in which local Chinese authorities can make judgments about how to proceed with policy reforms. The evolution of Chinese bureaucracy attests to the fact that "local leaders have a great leverage on determining local priorities" (So and Kao, 2014). Given this level of local autonomy in policy planning and implementation and trends of urbanization, it makes sense to focus on cities as cases of Chinese urban transportation policy decisions rather than the national government (Wan, Wang, and Sperling, 2013).

Among Chinese cities and as provincial-level municipalities, Beijing and Shanghai have recently demonstrated innovative policy implementation, experimenting with transportation policies including license plate lotteries and auctions aimed at restricting vehicle ownership. Moreover, they are also considered the pacesetters or engines for economic and socio-political development in China (Li, 2007). In addition to enjoying similar levels of policy innovation, both cities are comparable in size, economic and socio-demographic characteristics. Given their similarities, they are strong cases for comparative analysis.

At the same time, the selection of these two cities as case studies provides a unique opportunity to identify differences between the two cities and any factors that drive these differences. For example, due to a higher level of conservatism in Beijing, the role of public opinion may be less prominent than in the case of Shanghai, which possesses the image of a market-oriented, liberal, advanced city $(\mathrm{Li}, 2007)$. Beijing is the nation's capital, meaning that the city hosts the national government as well as the city government. While transportation policies and other developmental policies are primarily administered by the city government, due to geographic proximity to the national government, it may be fundamentally challenging to completely exclude the influence of the national government in transportation policy decision-making in Beijing.

\section{METHODOLOGY}

\subsection{Semi-Structured Interviews}

The research was conducted using principles from grounded theory, a methodology designed to

35 build theories from data about the social world such that "theories are 'grounded' in people's everyday experiences" (Knigge and Cope, 2006). Research using this approach involves iterative stages of data collection, coding and analysis, critical reflection on emerging themes and concepts, and constant comparison of the insights that evolve (Knigge and Cope, 2006, Knox Hayes, 2016).

40 Specifically, the study is conducted in a recursive manner using an iterative process in which preliminary interview findings influence the analysis of subsequent phases, including: 1) preliminary analysis to identify key factors that seem to most dominantly influence final transportation policy decisions in the selected cities; 2) analysis and grounded visualization of qualitative data to link actors and decision-making processes; and 3) surveys of government

45 officials' perception of factors that drive or inhibit transportation policy decisions by asking questions around specific transportation policy examples that they were directly involved in formulating (Knox Hayes, 2016). 
We conducted in-person semi-structured interviews with 32 individuals (see Table 1). Interviewees were selected using a snowball sampling method (Small, 2009) from governmental agencies, non-governmental organizations, and academia (see Table 1). Interviewees included city government officials who are both directly and indirectly participating at multiple stages of transportation policy decisions in the two cities. The government officials interviewed in both cities are members of technical research centers rather than those with decision-making authority at the top-levels of city government. These interviewees also include non-governmental professionals and academics because the city government frequently hosts research expert group meetings to seek advice on the validity and feasibility of certain transportation policy proposals.

Table 1. Number and affiliation of interviewees by type for each city.

\begin{tabular}{|c|c|c|c|c|}
\hline \multirow[b]{2}{*}{ Type } & \multicolumn{2}{|r|}{ BEIJING (N=16) } & \multicolumn{2}{|r|}{ SHANGHAI $(\mathrm{N}=16)$} \\
\hline & $\mathbf{N}$ & Affiliation & $\mathbf{N}$ & Affiliation \\
\hline Academia & 10 & $\begin{array}{l}\text { - Tsinghua University } \\
\text { - Beijing Jiaotong University }\end{array}$ & 5 & $\begin{array}{l}\text { - Tongji University } \\
\text { - Shanghai Maritime University }\end{array}$ \\
\hline $\begin{array}{l}\text { City } \\
\text { government }\end{array}$ & 2 & $\begin{array}{l}\text { - Transportation Committee } \\
\text { - Transportation Development } \\
\text { Research Center }\end{array}$ & 10 & $\begin{array}{l}\text { - Transportation and Port Research } \\
\text { Center } \\
\text { - Housing and Urban and Rural } \\
\text { Construction Management } \\
\text { Committee } \\
\text { - Maritime Safety Administration }\end{array}$ \\
\hline Professionals & 4 & $\begin{array}{l}\text { - World Bank } \\
\text { - Energy Foundation }\end{array}$ & 1 & - World Bank \\
\hline
\end{tabular}

Each interview lasted from 40 to 60 minutes and was conducted in Chinese. The first part of the interview featured a standard set of questions. These interview questions focused on the participant's experience of and actions within the transportation policy decision-making process in each city, personal involvement in certain exemplary policy cases, assessment of the current structure of transportation policymaking process, and observations of public engagement, and their discourses on transportation policy. The second part of the interview consisted of follow-up questions based on individual's responses in the first part.

\subsection{Data Analysis}

Interviews were transcribed, professionally translated, and uploaded to Atlas.ti software package for analysis. The interview transcripts were coded in three steps (Corbin and Strauss, 2008). First, the transcripts were coded to identify, categorize, and describe factors contributing to or obstructing policy reforms, decision-making procedure, actors involved, and relevant

25 organizational structure. Second, axial coding was used to relate open codes to one another and to identify associational relationships (Corbin and Strauss, 2008). The axial codes were finally coded into analytical categories to inform models for each of the two objectives of the study: identification of underlying contributors and obstacles in policy decision-making and detailed description of the entire process of transportation policy formulation at the city level. The analysis looks for instances where specific policy successes or failures have explicit connections to certain contributing or oppositional factors, as well as the context specific conditions which can be associated to the policy decision outcomes. Finally, supplementary survey data is presented to further validate some of the findings derived from the qualitative data analysis. 
Through iterative coding process, we identified key underlying factors that help determine the evolution of transportation policy decisions as well as when certain transportation policies become adopted while others do not. We were able to also illustrate and explain the detailed process leading to policy decisions, derived from in-depth, recursive discourse with the relevant participants directly involved in the process in the two cities.

\subsection{Supplemental Questionnaire Survey}

Interviews were complemented with a structured questionnaire survey that was distributed to and returned by individuals via email. Survey questions were designed to explore the specific contributors and obstacles to transportation policy decisions identified from the interviews. The survey was distributed to a snowball sample of 90 government officials who are involved in the transportation policymaking process in Shanghai, and we received 57 valid responses.

\section{CONTRIBUTORS AND OBSTACLES TO TRANSPORTATION POLICY DECISIONS}

15 Contributors to policy decision-making are ways in which policy decision can be facilitated by city governments. In our study, we explore to what extent contributors identified for city-level policy decisions in other domains apply to the context of transportation policy in Chinese megacities. From the coded interview data, we identify three prominent contributors to transportation policy decisions - policy learning from other cities, transportation informatization, and public opinion and four prominent obstacles to transportation policy decisions - public complaint, unilateral decision-making structure, lack of cross-departmental communication and coordination, and lack of adaptiveness in policy implementation. Figure 1 illustrates the relational connections among these key contributors and obstacles to city-level transportation policy decisions in China identified in this study. Many of these factors build on existing discussions of contributors of city-

25 level policymaking in general, but are evidenced for the first time in the transportation context in China. The following sections discuss each of these contributors and obstacles in turn, first providing a brief overview of relevant literature (where applicable) and then summarizing and discussing the interview results from this case study.

Figure 1. Relations among key contributors and obstacles to transportation policymaking in Chinese megacities.

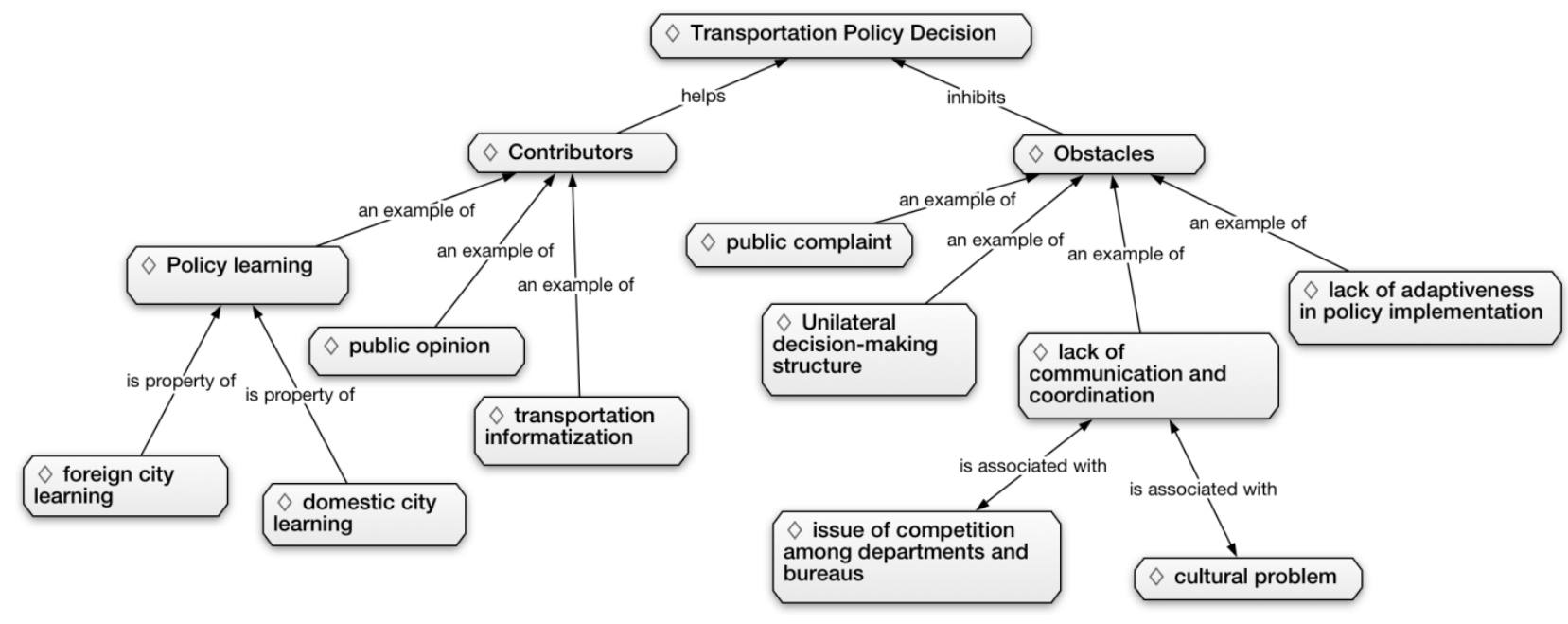




\subsection{Contributors to Policy Decisions}

\subsubsection{Policy Learning from Other Cities}

The concept of policy learning from other cities or lesson drawing refers to the idea that cities learn from transportation policy implementation in other cities both domestic and foreign. Dolowitz and Marsh helped formalize the study of policy transfer (between or within nations) as a result of strategic decisions taken by actors inside and outside government $(1996 ; 2000)$. While such a rational choice framework for policy transfer has been challenged (Peck, 2011), the framework of Dolowitz and Marsh continues to be used to analyze the role of voluntary policy transfer (lesson drawing or policy learning) in facilitating policy at the city (EU-Timms, 2011) and national (Chinga-Zhang and Marsh, 2016) levels. In the field of transportation, evidence shows that policy transfer is largely attributed to city officials (Marsden and Stead, 2011). In general, city government officials tend to value specific policy experiences by other cities because these policy experiences are derived from real-world cases (Marsden and Stead, 2011; Marsden et al., 2011). Often these are compelling because they incorporate objective data and emphasize tangible (as opposed to theoretical) outcomes (Marsden et al., 2011). City officials have a strong tendency to rely on policy learning because it is based on a documented 'implementation stories' and not just subjective accounts (Marsden and Stead, 2011). The results of this study further validate this claim and show that policy learning contributes to transportation policy decisions in large cities in China.

In our interviews, there is substantial evidence of learning between Chinese cities. For example, Shanghai government officials indicated that Shanghai's policies on how to plan lanes and parking sites for bike sharing systems are informed by the 'Guidelines on Regulating Bike Sharing' issued by Chengdu and Shenzhen. Additionally, a policy that restricted the registration of small cars in Beijing through a lottery was studied in comparison to an auction policy in Shanghai. Government officials in the two cities were quite confident that Beijing and Shanghai will continue to be models for other cities in China when it comes to adopting new transportation policies. This corroborates previous literature that identifies Beijing and Shanghai as past and current trendsetters in innovative transportation policymaking in China (Li, 2007).

A number of examples also demonstrate policy learning from foreign cities. Government officials in Beijing and Shanghai devote a tremendous amount of time and resources to studying other international cases and incorporate this data and analysis in their policy decisions:

BJTRC (Beijing Transportation Development \& Research Center) mostly focuses on collecting data and doing research... They research on the international cases, especially the successful cases, and then they collect data and make their own decision. And after that, they invite some experts from both universities and industries/companies to make suggestions to the existing report.

Several government officials at the Shanghai Transportation and Port Development Research Center explained that they visit other foreign cities like London, New York, Tokyo, Paris, Seoul, and Singapore to research transportation policy success cases and evaluate their feasibility and applicability to Shanghai. Specific policy examples include, Tokyo's subway, Seoul's rapid bus system, and Singapore's congestion charging.

While the validity and relevance of policy learning in the field of transportation is accepted as 
everyday practice, such a contributor should not be over-emphasized as the sole underlying approach to policy decisions in the transportation sector. There is also a possibility that more than one underlying contributor may drive policy adoption; for example, policy learning may initially drive adoption of new public transportation infrastructure such as bus lanes (by doing research on success stories in other cities), data driven simulations conducted by city-level research units may subsequently determine the feasibility or applicability of such policy, utilizing data as key evidence.

\subsubsection{Transportation Informatization}

10 Champions of evidence-based policy decisions claim that since data-driven policymaking relies on after-the-fact objective measurement, it is more likely to minimize policy failures. Thus, policy reform, they believe, ought to prioritize "evidentiary" decision-making (Howlett, 2009; Head, 2016; Arinder, 2016). Notably, the "policy analytical capacity" to argue that public policy is significantly determined by the analytical capacity of the responsible government entities

15 (Howlett, 2009). Mu, Mouter, and de Jong (2016) also underscore the importance of analytical information when making decisions on transportation policy options.

In our study, some participants identified transportation informatization as being an additional contributor to policy decisions. This term, coined by government officials in this study, refers to

20 the newly developed information technologies that provide more hands-on data, which can be utilized to formulate more accurately targeted transportation policies. Newly developed platforms that allow for additional collection of transportation data significantly help the policy decisionmaking process by generating more rigorous, data-driven research reports. These new information platforms include "customized station videos, mobile phone applications, and other computer

25 software." For example, government officials in Shanghai explained that transportation informatization has opened up access to real-time arrival information for buses at every station, increasing the convenience of the system for passengers. Higher public transportation ridership (and associated increase in public transportation revenues) can then be used as evidence in support of public transportation-related policies. Interview participants from both cities expressed confidence that such newly developing platforms of information will be critical in the facilitation of future transportation policy decisions. Transportation informatization may be a key catalyst towards more data-driven policymaking, commonly cited as a contributor to better policymaking (Howlett, 2009).

\subsubsection{Public Opinion}

In addition to policy learning and data-driven policymaking, bottom-up public participation has emerged as a potentially valuable contributor to urban policymaking, particularly when working with multisectoral problems such as transportation (Carpini et al., 2004). While public participation is seen as an established part of democratic government, it can contribute value even in top-down policymaking regimes. Increased public participation can help frame the policy problem in more accurate and viable ways than professionals and government officials acting alone (Fung, 2015). When decisions involve important ethical or material trade-offs, the general public may be best placed to adjudicate those trade-offs and provide information relevant to devising solutions and evaluating implementation (Fung, 2015). Finally, the general public can

45 sometimes become directly engaged in solving public problems and thus contribute additional resources through coproduction (Fung, 2015). 
While transportation policymaking at the city level in China still lacks formalized processes of public participation, in this study public opinion was identified by government officials as a third contributor to transportation policy decisions in China's largest cities. While public participation and coproduction of policy are well-developed topics in Western democracies, the general public is not directly involved in the policy formation process in China. While there may not be direct avenues of public participation, our interviews indicate that city government officials in charge of policy formation pay significant attention to public perception. Respondents in Shanghai in particular (less prominent in Beijing) suggest that the government actively collects reactions of the public by publicizing policy research reports online and reviewing public reactions before implementing a specific policy. For example, a draft policy report on ride-hailing was published on the internet to observe how the public reacted to that specific policy. Evidence also supported other means by which city governments in China constantly monitor public perception towards potential policy decisions, such as via telephone call centers and other social network platforms like Weibo. Through various media platforms, government officials, particularly in Shanghai, observe general public opinion and this knowledge contributes to transportation policy decisions.

\subsection{Obstacles to Policy Decisions}

\subsubsection{Lack of Cross-Departmental Communication and Coordination}

Based on the coding process, four primary obstacles to and challenges for transportation policy decisions in the two cities emerged from the data. Transportation policies in Chinese cities are primarily the responsibility of a municipal Transportation Committee and its subsidiary organizations. However, many transportation policies touch on issues related to housing, urban development, and the environment, and therefore necessitate close correspondence across several bureaus or departments within the city government. Due to the inherent organizational setting and notion of competition that exists among these departments, lack of communication and coordination among key bureaus and department as one of the key obstacles to transportation policy implementation.

For example, one of the government officials in Shanghai expressed difficulties in getting ideas developed into a policy decision when that policy decision involves other relevant departments:

If I promote it up to my direct leader, it won't be that difficult. But when it involves the peer department, or peer-crossed department, which sometimes indeed will happen, it will become difficult. Because once the peer department is involved, my leader needs to communicate with them, instead of me. In China, as for the coordination and communication including that of information and some other matters between government departments, the two departments involved need to coordinate at the city government level.

40 Interviews also suggested that departments within the same city government are reluctant to share information, even when certain policy outcomes rely heavily on cross-departmental correspondence - such as transportation policies like bus rapid transit that are closely associated with the housing and construction department. In particular, the issue of competition arose between two departments after a change in organizational structure in 2014, when Shanghai

45 Transportation Committee absorbed a portion of functions in transportation of the Shanghai Construction and Transportation Authorities. But since 2014, the Shanghai Housing and Urban 
and Rural Construction Management Committee is still not willing to give up some of its role in transportation due to unclear division of functionality.

This identification of the lack of cross-departmental communication and coordination as a key obstacle in city-level policymaking in China is corroborated by other studies. With reference to the organizational structure in Wuhan, Spear (2006) explains that a main challenge is for key agencies to cooperate and to reconcile the "overlaps and gaps in responsibility." Such intrinsic tensions further inhibit possibilities for closer correspondence, which may be critical in pushing certain transportation policy ideas into policy decisions. Huang (2003) also underscores the importance of data sharing among governmental agencies, pointing out that information sharing is an inherent cultural challenge. In China, open discussion and cross-departmental exchange in information is not widely accepted. As indicated in Figure 1, cultural value coupled with the established hierarchical decision-making structure is closely associated with the lack of active crossdepartmental coordination.

\subsubsection{Public Complaint}

Interview participants also identify public complaint as one of the key obstacles to transportation policy decisions. While the general notion of public opinion may facilitate a transportation policy decision, public complaint may inhibit immediate policy adoption. One prominent example is the potential implementation of congestion charging in both Beijing and Shanghai. Participants in Beijing, in particular, emphasized that congestion charging was seriously considered over the past five years after careful study of similar systems in London and Singapore. However, the policy was not adopted because the public was not favorable towards the idea of congestions charging. One official from Beijing's said:

[When it comes to] congestion charging, mainly the pushback comes from local residents. They make a big noise on the Internet, and they don't quite understand the logic behind the congestion charge [or charging]. It's not that straightforward. The people feel, "I have the right to drive around. Why do you charge me extra money for my existing rights?" It's part of the communication issue.

Other participants in Beijing suggested that congestion charging policy may have failed to gain support because a large proportion of the city population resides in the inner city. In contrast to the case of public complaint stalling the implementation of congestion charging, the Beijing city government was quick to adopt "bus only lanes" since the public did not seem to express disagreement to such a policy initiative.

Interviews in Shanghai also suggest that public complaint can be an obstacle in policy decisionmaking. In Shanghai, for any issues related to city construction and transportation, anyone can dial ' 12319 ' and file a complaint. Thus, depending on the type of policy and city, public opinion can be both a contributor and a hurdle to immediate transportation policy decisions.

\subsubsection{Unilateral Decision-making}

Another obstacle in implementing transportation policy is unilateral decision-making.

45 Government officials in both cities commented on how one or two individuals in top leadership positions in the city government make final policy decisions, and that these decisions may not always reflect the details or recommendations of research reports. In both cities, government 
officials in research units under the city's Transportation Committee (i.e. technical staff) expressed their lack of agency in the decision-making process. It is clear that in most cases, either the mayor of each city or the leader of each Transportation Committee makes the final decision on transportation related policy decisions. Our case study corroborates findings by Matsumoto (2007), who finds that mayors in Chinese cities have enormous discretion over transportation policy decisions and budget planning compared to mayors in other international cities.

This unilateral decision-making evokes an important tradeoff between the efficiency of transportation policy implementation and the efficacy of transportation policy. While having centralized decision-making authority at the discretion of the mayor may expedite the adoption of certain transportation policies, such unilateral policy decisions may not be the product of political strategery rather than objective, analytical data that suggests effectiveness in addressing actual needs. In extreme cases, such decisions may primarily be driven by an individual mayor's desire to improve his/her performance record for career promotion (de Jong, 2013). Based on case studies in Dalian, $\mathrm{Mu}$, Mouter, and de Jong (2016) claim that transportation policy decision-makers use analytical information in a symbolic way, as a "rational ritual." They suggest that the policy research process and resulting analytical information in China is pursued to create the image of a logical process rather than to directly inform the policy decision-making process $(\mathrm{Mu}$, Mouter, and de Jong, 2016). Therefore, analytical reports can be highly dependent on political guidance and Chinese city government leaders are capable of justifying their decisions by pulling in selective resources that purposefully support the viability of their decisions $(\mathrm{Mu}$, Mouter, and de Jong, 2016). Under such circumstances, the analytical information is no longer neutral or transparent (Mu, Mouter, and de Jong, 2016) and despite logical, investigative frameworks political leaders make ultimate policy decisions unilaterally.

\subsubsection{Lack of Adaptiveness}

Associated with the above concept is the fact that it takes a long time to implement transportation policies. In certain cases, initial policy recommendations made by research units may become outdated before policy is actually implemented. Many interview participants suggested that the current transportation policy decision process is inefficient because it lacks the capacity to adapt to ever-changing environments in local contexts. The following statement made by one of the government officials in Shanghai clearly demonstrates how the current transportation policymaking process does not quickly respond to prominent transportation- related problems in the city:

In many cases, these policies are just for back-up/reserve. For example, maybe this year, we put forward some policies related to renewable energy or public transportation. Then in the next year or in several years, the earlier problem becomes a hot issue and has aroused wide attention. However, the question is, after several years, the policies we have made earlier may not be suitable for the needs of current development. As a matter of fact, when making policies several years ago, we didn't consider the situation very well. I think the best choice is to make a policy that is needed to solve the existing problem and immediately implement the policy and achieve the desired result. In contrast, if we have researched all policies and established them only for back-up, after two or three years, the situation would have changed. Even if we have had many back-up policies to use, as they don't meet the development needs any longer, we have to remake the policy when we 
really need it. In such case, a lot of time, resources and manpower would be wasted. The process of transforming a policy in theory into practical implementation is not so smooth, and this is mainly due to a critical problem, that is, we haven't done enough in achieving adaptive or dynamic effect.

Likewise, interview participants from both cities cite a need to improve the current policy decision-making process to implement transportation policies in a more effective and efficient manner.

\subsection{Survey Results and Contributors to Transportation Policy Decisions}

In addition to the in-depth interviews, we conducted the questionnaire survey among government officials in Shanghai. In particular, here we look at responses to four Likert-format questions on the prevalence of policy learning from both domestic and foreign cities and levels of awareness of public opinion and media coverage in Shanghai:

151 . 'I believe my organization/department/bureau studies best transportation policy cases in other cities in the world'

2. 'I believe my organization/department/bureau studies best transportation policy cases in other cities in China'

3. 'I am aware of the media coverage on current transportation policies'

4. 'I am aware of the public perceptions of current transportation policies'

For each question, respondents were asked to rank each statement from 'strongly agree' to 'strongly disagree'. The survey results $(\mathrm{N}=57)$ are summarized in Figure 2. An overwhelming majority of respondents agreed with all four statements, corroborating the findings from the qualitative interviews that officials participate in policy learning from both domestic and foreign cities and pay attention to public opinion and the media.

There is evidence that government officials in Shanghai participate in policy learning from both domestic and international cities, although officials look to international best-practice more than domestic experience. These survey results corroborate findings from the qualitative interviews that identified policy learning as a contributor to transportation policymaking in both Shanghai and Beijing. In regards to awareness of public perception and media coverage of current transportation policies, the majority (60\%) of Shanghai government officials partially to strongly agreed. An even greater proportion of officials expressed awareness of media coverage on transport policies. This reinforces the finding that public opinion is a contributor to mobility policy decisions in Chinese cities, but suggest that it is not quite as common a practice for government officials as policy learning.

The following section further elaborates on the transportation policymaking process and maps where these contributors and obstacles fit within the actors and steps of this policy decisionmaking. 
Figure 2. Agreement with statements on policy learning from other cities and awareness of public opinion among Shanghai government officials $(\mathbf{N}=\mathbf{5 7})$.

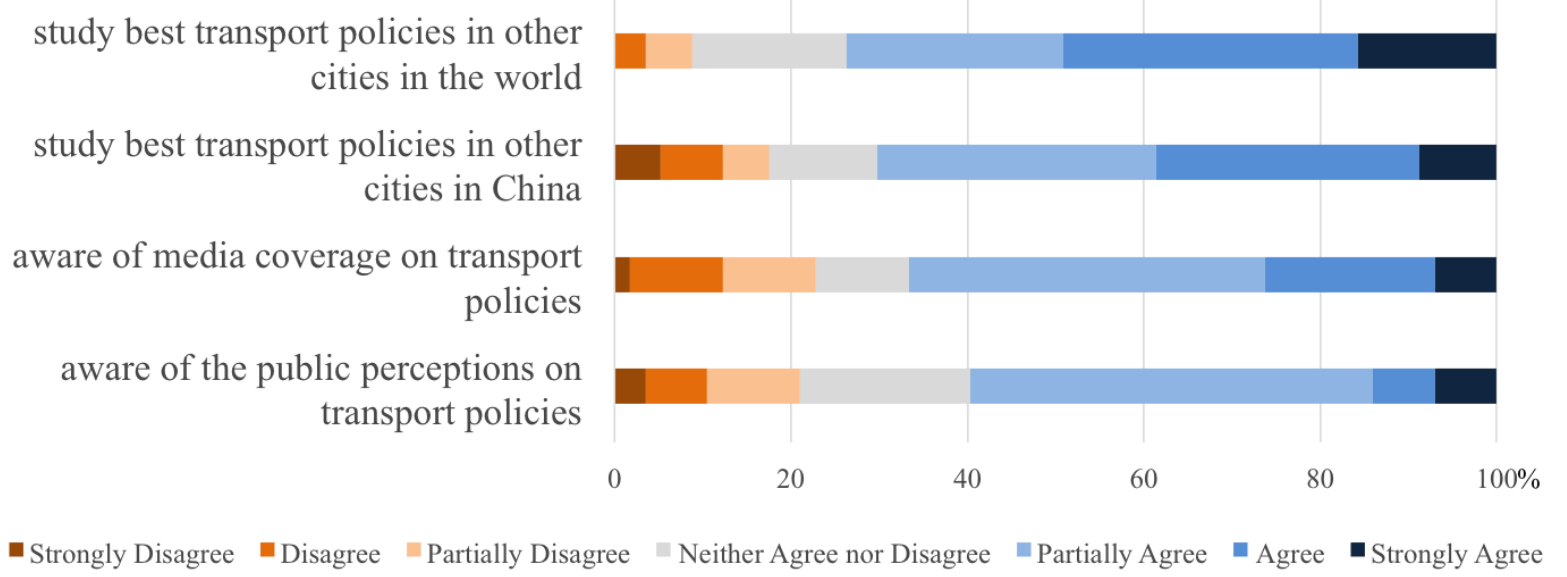

\section{PROCESSUAL MODEL OF TRANSPORTATION POLICY DECISIONS}

In addition to identifying key contributors and obstacles to transportation policy decisions in Chinese cities, coded interview data also clarify the process by which the city governments of Beijing and Shanghai arrive at transportation policy decisions. While there are studies that (i) introduce the institutional structure of key organizations involved in transportation related matters (Huang, 2003; Spear, 2006), (ii) describe the general process of how certain large scale transportation infrastructure projects are instigated (from conception, feasibility study, and approval to operation) (Mu, Mouter, and de Jong, 2016), and (iii) emphasize the role city governments can play in addressing the complex interplay of constantly changing physical characteristics such as demographics, housing developments, motorization and people's travel demand (Shen, 2002), to the author's knowledge there is not yet a study that explains the internal decision-making process of transportation policies at the city level in China. Extending beyond descriptions of organizational distribution and responsibility, this section offers a detailed process of city-level transportation policymaking, carefully compiled from the analyzed data. It also connects each of the contributors and obstacles identified in the previous section to the relevant actors and policy flows within this process.

In brief, we find that transportation policies at the city level are responsive to transportation problems or strong demand from the general public. Once a problem is identified, the transportation committee in each city tasks their respective research centers to analyze the problem and possible policy responses and produce recommendations. These recommendations may

25 translate into actual policy adoption at the city transportation committee level, or be submitted to the city government leadership for final decision. Figure 2 summarizes the overall process leading to transportation policy decisions in the two representative cities in China, including how certain contributors and obstacles identified in Section 3 connect to this process.

\subsection{Responding to a Transportation Problem and the Importance of Public Opinion}

Interviews suggest that in most, if not all transportation policy cases, policy decisions are initiated in response to prominent and prolonged transportation-related problems. In interviews, government officials and external experts all observed that only when problems like air pollution or severe congestion become serious enough did the city government begin the process to issue 
specific policies to remedy these problems. The following is a quote from a city government official from Shanghai.

[The government] can't sense some problems, predict the underlying consequences and take some measures in advance but only begin to find solutions until the problems are very prominent and intense.

While it may be natural that policies are inherently designed to address problems, interview data also indicate that such a purely responsive transportation policymaking process may prohibit proactive and predictive measures.

Moreover, coded findings indicate that public complaints, identified as an obstacle to policy decisions in Section 3.1, may in some cases trigger city government to take concrete action by highlighting the transportation issues that need a policy response. For example, congestion has

15 been a prolonged issue in both Beijing and Shanghai and the general public continues to complain to city government to take affirmative action to mitigate these problems. Pressure from the public led to government consideration of adopting congestion charging policy and other intermediate measures. Via specific action such as posting complaints online on social networks platforms, or filing complaints by phone, the general public plays a role in asking for concrete policy action from the city government.

In parallel, So and Kao (2014) claim that despite the authoritarian regime in China, the public policymaking process is gradually shifting towards greater civic engagement, unconventional forms of political participation such as street protests, public participation, and internet discussions (So and Kao, 2014). In extreme cases, they point out that street protests have been particularly effective as a means for the public to get its message across, since Chinese local governments have been quite concerned about maintaining political stability (So and Kao, 2014). Our interviews seem to corroborate these findings, suggesting that, despite lacking a formal public participation process, Chinese cities account for both public opinion and public complaint when making transportation policy decisions.

\subsection{Initial Response at the National and City Level}

When a certain transportation problem receives sufficient attention, both the Ministry of Transportation (national government) and the Transportation Committee in each city begin to take action. The national government sets general targets or goals, as exemplified by its 13th Five-Year Plan, which lays out general targets to address challenges including urbanization, transportation, and climate change (Koleski, 2017). However, the Ministry of Transportation does not usually dictate specific transportation policies for cities to meet these targets. Instead, the interview results indicate that once the Ministry of Transportation recognizes a nation-wide transportation-related problem, it issues an "instructive suggestion" to the 31 provinces, cities, or autonomous regions nationwide to come up with localized solutions that fit within the national agenda. The specific research, study, and adoption of transportation policies occur within each autonomous region as evidenced by the following statement made by a city government official in Shanghai:

As for the specific transportation policies, they are now all decided by local departments or adjusted according to local conditions. We can understand it from the policy in Shanghai. 
Alternatively, in certain cases, a city government's Transportation Committee may react to smaller, more localized transportation problems without a national-level directive. In either case, whether the initiation begins from the Ministry of Transportation (at the national-level) or the Transportation Committee (at the city level), the process then continues to the research centers under each city government.

\subsection{City Research Centers}

Based on the particular transportation-related problem identified by the Transportation Committee, the respective research center - like the Shanghai Transportation and Port Development Research Center or the Beijing Transportation Development Research Center - in each city is assigned the policy task. The appropriate research center (by area of expertise) conducts internal surveys to test certain policy ideas. Government officials in the research centers in both cities indicated that they usually do not share the survey reports with the Transportation Committees or Ministry of Transportation.

Then the research centers generate research reports that combine the internal survey results with other materials that are collected from existing research or from the experiences of other cities. This is where learning from other foreign and domestic cities, previously identified as a key contributor, is incorporated in the transportation policy decision. One important finding in this phase of the process is that, instead of blindly adopting best case practices from what other international cities have done, Chinese officials contextualize the lessons learned with their own analysis based on internal survey results. The notion of contextualization in policy transfer agrees with previous studies into the re-association of successful policy ideas into the new institutional environment and domestic context (de Jong, 2013).

Then, once the research report is produced, the respective research centers host expert group meetings to analyze and discuss the research report on the feasibility of possible policy decisions. During this phase, experts like academics from local universities provide their own opinions and suggestions on the proposed research reports. Through revision and final review meetings internally, the revised research report is submitted back to the Transportation Committee.

\subsection{Final Policy Decision}

The interviews indicate that the final transportation policy decisions are either made by the city government leadership - the mayor or the party secretary - or the Transportation Committee. While the former process depends largely on the mayor's individual discretion, the latter involves additional steps to "absorb the opinion from [the] social public" by publicizing policy research documents. Then, depending on the public reaction, policy implementation decision may be announced or the Transportation Committee may withhold immediate implementation decision due to unfavorable local acceptance. This is the reason why the general public appears twice in the processual model in Figure 3: once as a contributor in the problem initiation phase and again as an obstacle during the consultation phase at the Transportation Committee level.

The transportation policy decision-making process may vary by the type and scale of policies. For example, when it comes to specific, smaller scale policies - like providing free subway passes for the elderly in Shanghai - the implementation decision can be directly made by the Transportation Committee. However, larger scale policies like the introduction of a car license plate auction must 
be submitted to the city government leadership for review. It is this phase in the process where the obstacles such as unilateral decision-making and lack of adaptive policymaking become most prominent. Coded data indicate that when recommendations on larger scale policies are submitted to the city government, officials in leadership positions possess full discretion to make policy decisions regardless of the details of the technical reports. In other words, even though the researchers in the subsidiary bodies provide reports on data analysis and modeled results, when decisions move to higher levels of government their recommendations may not be implemented at all. Similarly, interviews suggest that since local conditions continually change over time, when policies are held for long periods some of the policy recommendations may become outdated and may require new research processes with a new set of policy research results.

The processual model is not an exclusive or exhaustive summary of all transportation policymaking processes in all Chinese cities. However, the coded results reveal a very similar procedure for the two case cities on how transportation policy ideas are generated and how such ideas are re-shaped, altered, and substantiated by multiple actors and public opinion until finally implemented. 


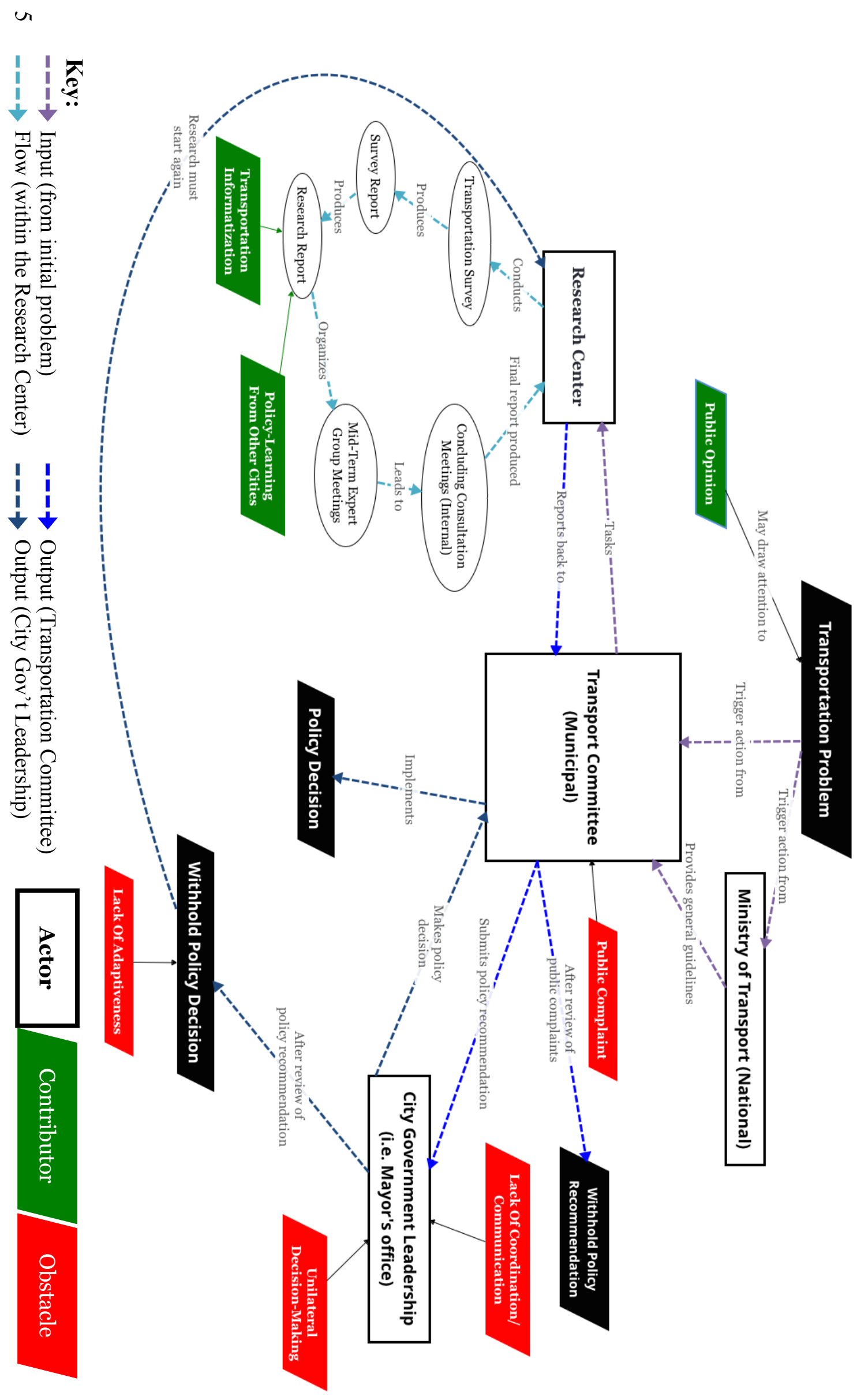

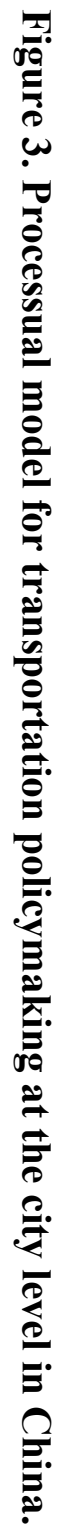




\section{DISCUSSION}

We acknowledge that using 32 interviews in two megacities can only offer a first impression of the current transportation policymaking process at the city level in China. However, the findings in this paper are useful to inform both the academic community and the Chinese national and local governments. Future research can replicate, verify, and update the identification of contributors, obstacles, or the processual model introduced in this research, through application to other Chinese cases. Government officials may take note of what contributors to policymaking might be fostered at the city level or how to remove obstacles. For example, government officials may wish to support policy learning and transportation informatization at the research center level and to establish transparent communication channels between higher-level political decision-makers and research staff empowered with a comparative, case-study knowledge and new forms of information technology. These communication channels may help to reduce unilateral decisionmaking and encourage adaptiveness in the policymaking process. In addition, city-governments may endeavor to clarify roles over transportation functions and encourage data sharing among different departments for large-scale policy decisions that affect transportation, housing and development, construction, and other sectors.

In addition to supporting existing contributors, government officials in Chinese cities may want to build on positive experiences of policy experimentation in other contexts as a way to build adaptivemence in their transportation decision-making. China has been lauded for its national policy process of decentralized experimentation, in which central policymakers encourage local officials to problem-solve and then model national policy formulation on successful local experience (Heilmann, 2008). At the city level, Mei and Liu (2014) demonstrate that urban housing policymakers in Chinese cities are conscious of the value of experimentation in policy design, initiating small-scale experiments on different policy options, then finally, making policy implementation decisions based on the outcomes of these experiments. While the idea of learning through purposeful policy experimentation and adaptiveness is well accepted, our interviews suggest that in transportation policymaking at the city level, bureaucratic realities and processes fall short. Therefore, this study suggests that Chinese cities may benefit from more formalized processes for policy experimentation in the transportation context.

In addition, this study suggests further research and attention is needed to address public participation in the policymaking process at the city level in China. In 2014, China's national government issued the 'National New-Type Urbanization Plan' (2014-2020), which promoted goals of urban sustainability and drew attention to encouraging and supporting citizen participation in the process of new-type urbanization. Despite this national goal, literature suggests that the policymaking processes and cultural practices in China's urban development are still imbued with a distinctive top-down mode of decision-making in which public participation is not well institutionalized in strategy development ( $\mathrm{Li}$ and de Jong, 2017). A case study in Suzhou

40 suggests that the extent of citizen participation differs between the decision-making and implementation phases, with local government taking a top-down approach to strategy development but involving citizens in its implementation ( $\mathrm{Li}$ and de Jong, 2017). Other studies also suggest that government authorities still "regard public participation first and foremost as a means to increase the effectiveness of policy measures and officials leave no doubt that the 45 promulgation of... goals and policies should remain an exclusively state affair" (Martens, 2006). Many see this involvement of the public during downstream implementation of policy rather than in policy formation is deeply rooted in traditional Chinese "principle of mass participation," where 
the focus is on participating in the implementiation of government plicies, plans, or projects rather than the Western concept of participation that focuses on the development of the policies themselves (Li, Ng, and Skidmore, 2012). In view of this cultural difference, it is perhaps not a surprise to that public participation, in the Western sense, is limited in many policymaking domains in China.

Our interviews provide a more nuanced understanding of public involvement in city-level transportation policymaking. Our results suggest that public opinion plays an indirect role as a contributor to early project initiation by drawing government attention to key transportation issues, while public complaint acts as an obstacle to policy implementation. Therefore, although there may be no formalized public participation process during policy development, we found that technical government officials involved in strategy and policy development are aware of and responsive to public opinion expressed through call centers, government websites, and print and social media. However, by not involving constructive public contributions in early planning and the development of policy, public complaint - and other traditional forms of (ex-post) public involvement in "decide-announce-defend" style policymaking - proves an obstacle in legislative procedure (Enserink and Koppenjan, 2007).

The role of the public remains ad-hoc and transportation policymaking at the city level in China may benefit from carefully structured, formalized processes of public participation that constructively capture public opinion, particularly during policy formation (between policy initiation and implementation). However, any such "democratization" of the policymaking process may need to take different forms than those commonly found in the West to speak to the different cultural and historical view on participation in political ans social affairs held by Chinese citizens (Martens, 2006; Li, Ng, and Skidmore, 2012).

\section{Variations in Beijing and Shanghai}

As explained in Section 1.2, the cities of Beijing and Shanghai are similar across a number of attributes including population size, area of land development, degree of economic development, and diversity in transportation policy adoption. From interviews with government officials in both of these cities, we identified a common processual model for transportation policy decisions, incorporating key contributors and obstacles. However, there are variation across departments and bureaus within each city (dependent on an individual leader's style or the key functions of an organization). Other differences between the two cities appear to be steeped in underlying cultural differences. For example, multiple interviewees pointed out that Shanghai city government in general is more visionary than Beijing. The following is an exemplary remark by one of the government officials in Shanghai:

I think Shanghai and Beijing are quite different. Beijing is like problem-driven. It is the congestion that people complain, and it's more like rescue-type of policy. It's not very visionary, not like Shanghai. And also, as compared to Shanghai and Shenzhen, which is more market-oriented economy, I think people are more open to innovations, like some of the bottom-up good exercise get absorbed in the policymaking process much easier than here.

While in both cities the initial policy idea is driven by intensification of transportation-related problems, the interviews suggest that Beijing is more likely to be problem-driven than Shanghai. 
Shanghai is presented as more visionary in terms of policy formation. Participants in Shanghai suggested that those in top leadership positions with decision-making authority in their city were more optimistic towards policy innovation compared to those in Beijing. Distinctions between the cities such as these are important, but are not necessarily captured in our current processual model. We emphasize that the discussion on the Beijing and Shanghai variation is only suggestive, given the limited number of interviews and, more importantly, the asymmetry of participant mixtures between the government, academia and NGO in Shanghai and Beijing.

\section{CONCLUSION AND FUTURE WORK}

10 Through iterative qualitative analysis of primary interviews of government officials, this research identifies key contributors and obstacles to transportation policy decisions in Beijing and Shanghai, China. For the first time in existing scholarship, we map the process of transportation policy decisions among different governmental actors in Beijing and Shanghai. The processual model for transportation policy decisions described in this paper is drawn from similarities among 32 interviews with government officials, academics, and transportation professionals in only two megacities, so it should continue to be validated and developed by applying it to other cities like Hangzhou or Shenzhen to expand its applicability. Further, key contributors and obstacles to policy decisions identified from the interview data may be tested in other Chinese cities in the transportation sector, other international cities in the transportation sector, other sectors besides transportation, and other stages or phases of city-level public policymaking processes. In particular, government officials and participants directly involved in the process of policy formulation in these cities, who strive to improve the current process to engender more effective transportation policies, ought to foster the contributors and remove the obstacles identified in this study.

While future work remains to refine the processual model and validate its applicability to other cities in China, the authors hope that this study will contribute to the broader discussion on the ways in which transportation policy is managed at the city rather than national-level in China and other countries. As the world urbanizes, cities play a growing role in policymaking and the shape of urban transportation patterns; we must understand and bolster existing policymaking processes, and remove obstacles to them, if we want cities to be able to effectively shape the future of urban transportation and development.

\section{REFERENCES}

Alam, M.A. and F. Ahmed. 2013. Urban Transport Systems and Congestion: a Case Study of Indian Cities. Transport and Communications Bulletin for Asia and the Pacific, No. 82, pp. 33-43.

Arinder, M. K. 2016. Bridging the Divide between Evidence and Policy in Public Sector Decision Making: A Practitioner's Perspective. Public Administration Review, Vol. 76, No. 3, pp. 394398. http://dx.doi.org/10.1111/puar.12572

Carpini, M. D., F. L. Cook, and L.R. Jacobs. 2004. Public deliberation, discursive participation, and citizen engagement: a review of the empirical literature. Annual Review of Political Science, Vol. 7, No. 1, pp. 315-344. https://doi.org/10.1146/annurev.polisci.7.121003.091630

Corbin, J. and A. Strauss. 2008. Basics of Qualitative Research: Techniques and Procedures for Developing Grounded Theory. Sage Publications, Inc., Thousand Oaks, California.

de Jong, M. 2013. China's Art of Institutional Bricolage: Selectiveness and Gradualism in the policy Transfer Style of a Nation. Policy and Society, Vol. 32, No. 2. pp. 89-101. 
doi:10.1016/j.polsoc.2013.05.007.

Dolowitz, D. P., and Marsh, D. 1996. Who learns what from whom: a review of the policy transfer literature. Political Studies, XLIV, pp. 343-357.

Dolowitz, D. P., and Marsh, D. 2000. Learning from abroad: The role of policy transfer in contemporary policy-making. Governance: An International Journal of Policy and Administration, Vol. 13, No. 1, pp. 5-24.

Enserink, B. and Koppenjan, J. 2007. Public participation in China: sustainable urbanization and governance. Management of Environmental Quality: An International Journal, Vol. 18, No. 4, pp. 459-474

Fung, A. 2015. Putting the public back into governance: the challenge of citizen participation and its future. Public Administration Review, Vol. 75, pp. 513-522. http://archonfung.net/docs/articles/2015/Fung.PAR2015.pdf

Gakenheimer, R. 1999. Urban Mobility in the Developing World. Transportation Research Part A: Policy and Practice, Vol. 22, No. 7-8, pp. 671-689. doi:10.1016/S0965-8564(99)00005-1.

Head, B.W. 2016. Toward More "Evidence-Informed” Policy Making? Public Administration Review, Vol. 76, No. 3, pp. 472-484. http://dx.doi.org/10.1111/puar.12475

Heilmann, S. 2008. From local experiments to national policy: the origins of China's distinctive policy process. The China Journal, No. 59, pp. 1-30.

Howlett, M. 2009. Policy analytical capacity and evidence-based policy-making: Lessons from Canada. Canadian Public Administration, Vol. 52, No. 2, pp. 153-175. http://dx.doi.org/10.1111/j.1754-7121.2009.00070_1.x

Huang, Z. 2003. Data Integration for Urban Transport Planning. Ph.D. Thesis, Faculty of Geograhical Sciences, Utrecht University, the Netherlands.

Li, T.H., Ng, S.T., and Skitmore, M. 2012. Public participation in infrastructure and construction projects in China: From an EIA-based to a whole-cycle process. Habitat International, Vol. 36, No. 1, pp. 47-56.

Knigge, L.D. and M. Cope. 2006. Grounded visualization: Integrating the analysis of qualitative and quantitative data through grounded theory and visualization. Environment and Planning A, Vol. 38, No. 11, pp. 2021-2037. http://dx.doi.org/10.1068/a37327

30 Knox Hayes, J. 2016. The Cultures of Markets: The Political Economy of Climate Governance. Oxford University Press, Oxford, U.K.

Koleski, K. 2017. The 13th Five-Year Plan. U.S.-China Economic and Security Review Commission Staff Research Report. https://www.uscc.gov/sites/default/files/Research/The\%2013th\%20Five-Year\%20Plan.pdf

Li, C. 2007. The Leadership of China's Four Major Cities: A Study of Municipal Party Standing Committees. China Leadership Monitor, No. 21, pp. 1-19.

Li, H. and de Jong, M. 2017. Citizen participation in China's eco-city development. Will 'newtype urbanization' generate a breakthrough in realizing it? Journal of Cleaner Production, Vol 162, pp. 1085-1094. https://doi.org/10.1016/j.jclepro.2017.06.121

Liang, Y. 2014. Relationship between Local Government Management and Community Autonomy in China. Business and Public Administration Studies, Vol. 8, No. 2.

Marsden, G. and D. Stead. 2011. Policy transfer and learning in the field of transport: A review of concepts and evidence. Transport Policy, Vol. 18, No. 3, pp. 492-500. https://doi.org/10.1016/j.tranpol.2010.10.007

45 Marsden, G., K. T. Frick, A. D. May, and E. Deakin. 2011. How do cities approach policy innovation and policy learning? A study of 30 policies in Northern Europe and North America. Transport Policy, Vol. 18, No. 3, pp. 501-512. 
http://dx.doi.org/10.1016/j.tranpol.2010.10.006.

Martens, S. 2006. Public participation with Chinese characteristics: Citizen consumers in China's environmental management. Environmental Politics, Vol. 15, No. 2, pp. 211-230.

Matsumoto, N. 2007. Analysis of Policy Processes to Introduce Bus Rapid Transit Systems in Asian Cities from the Perspective of Lesson-Drawing: Cases of Jakarta, Seoul, and Beijing. Air Pollution Control in the Transportation Sector: Third Phase Research Report of the Urban Environmental Management Project, pp. 351-372.

Mei, C. and Z. Liu. 2014. Experiment-based Policy Making or Conscious Policy Design? The Case of Urban Housing Reform in China. Policy Sciences, Vol. 47, No. 3, pp. 321-337.

Mu, R., N. Mouter, and M. de Jong. 2016. Strategic Use of Analytical Information in Transport Planning in China: How is it Different from Western Democracies? Journal of Urban Technology, Vol. 23, No. 2, pp. 3-22. http://dx.doi.org/10.1080/10630732.2015.1102424

Peck, J. 2011. Geographies of policy: From transfer-diffusion to mobility-mutation. Progress in human geography, Vol. 35, No. 6, pp. 773-797

Peng, Z.-R. 2005. Urban transportation strategies in Chinese cities and their impacts on the urban poor. $85^{\text {th }}$ Annual Meeting of the Transportation Research Board, Washington, D.C.

Saikawa, E. 2014. China's War on Air Pollution. China Currents, Vol. 13, No. 2.

Shen, Q. 2002. Urban Transportation in Shanghai, China: Problems and Planning Implications. International Journal of Urban and Regional Research, Vol. 21, No. 4, pp. 589-606. doi: 10.1111/1468-2427.00103.

Small, M.L. 2009. 'How many cases do I need?': On science and the logic of case selection in field-based research. Ethnography, Vol. 10, No. 1, pp. 5-38. http://journals.sagepub.com/doi/pdf/10.1177/1466138108099586

So, B.W.Y. and Y. Kao (eds). 2014. The Changing Policy-Making Process in Greater China. Routledge, New York, NY. http://media.hoover.org/sites/default/files/documents/CLM21CL.pdf

Spear, J. 2006. Urban Transport Schemes in China and Lessons from International Experience. Association for Eurpean Transport (AET) annual European Transport Conference, Strasburg, France, 2006. http://abstracts.aetransport.org/paper/download/id/2338

Timms, P. 2011. Urban transport policy transfer: "bottom-up” and “top-down” perspectives. Transport Policy, Vol. 18, pp. 513-521.

Wan, Z., X. Wang, and D. Sperling. 2013. Policy and politics behind the public transportation systems of China's medium-sized cities: Evidence from the Huizhou reform. Utilities Policy, Vol 27, pp. 1-8. http://dx.doi.org/10.1016/j.jup.2013.07.002

Wang, R. 2010. Shaping urban transport policies in China: Will copying foreign policies work? Transport Policy, Vol. 17, No. 3, pp. 147-152. http://dx.doi.org/10.1016/j.tranpol.2010.01.001

Woetzel, J., L. Mendonca, J. Devan, S. Negri, Y. Hu, L. Jordan, X. Li, A. Maasry, G. Tsen, and F. Yu. 2009. Preparing for China's Urban Billion. McKinsey Global Institute, McKinsey\&Co, pp.1-540. http://www.mckinsey.com/insights/urbanization/preparing for urban billion in china.

Yang, Z. 2013. 'Fragmented authoritarianism' - the facilitator behind the Chinese reform miracle: a case study in central China. China Journal of Social Work, Vol. 6, No. 1, pp. 4-13. http://dx.doi.org/10.1080/17525098.2013.766622

45 Zhang, Y. and Marsh, D. 2016. Learning by doing: the case of administrative policy transfer in China. Policy Studies, Vol. 37, No. 1, pp. 35-52. http://dx.doi.org/10.1080/01442872.2015.1107959 